American Journal of Agricultural and Biological Sciences 6 (4): 517-520, 2011

ISSN 1557-4989

(C) 2011 Science Publications

\title{
Effect of Critical Processing Variables on Sesame Milk Quality
}

\author{
${ }^{1}$ Ibrahim Afaneh, ${ }^{2}$ Khaled Abu-Alruz, ${ }^{3}$ Jihad M. Quasem, ${ }^{4}$ Ahmad Sundookah, \\ ${ }^{5}$ Jehad Abbadi, ${ }^{1}$ Suleiman Alloussi and ${ }^{1}$ Saleh Sawalha \\ ${ }^{1}$ Department of Food Science and Technology, Faculty of Science and Technology, \\ Al-Quds University, P.O. Box 20002, Jerusalem-Palestine, Israel \\ ${ }^{2}$ Department of Nutrition and Food Technology, Faculty of Agriculture, \\ Mutah University, Karak, Jordan \\ ${ }^{3}$ Deanship of Educational Services, Taibah University, Al-Madina Almnura, Saudi Arabia \\ ${ }^{4}$ Department of Nutrition and Food Science, Faculty of Allied Medical Sciences, \\ Applied Science University, Amman, Jordan \\ ${ }^{5}$ Jehad Abbadi, Biology Department, College of Science and Technology, \\ Al-Quds University, Jerusalem-Palestine, Israel
}

\begin{abstract}
Problem statement: In previous study sesame milk was developed. The developed milk had slightly acceptable dispersion stability and taste and there were a need to improve it. Approach: Dispersion stability and taste were improved by investigating the interaction effects of sesame seed to water ratios (10 or 12 or $14 \%$ sesame seeds) and different pasteurization treatments $\left(65^{\circ} \mathrm{C}-30 \mathrm{~min}\right.$ or $75^{\circ} \mathrm{C}-5 \mathrm{~min}$ or $\left.85^{\circ} \mathrm{C}-5 \mathrm{~min}\right)$. Results: The best sesame seed concentration was $12 \%$ and the best heat treatment was $85^{\circ} \mathrm{C}-5 \mathrm{~min}$. Conclusion/Recommendation: Sesame seed concentration and heat treatment of sesame milk had significant effect on sesame milk dispersion stability and sensory properties.
\end{abstract}

Key words: Sesame milk, dispersion stability, heat treatment

\section{INTRODUCTION}

There is a great interest in developing new products from decorticated sesame seed due to its nutritional (Evans and Bandemer, 1967; Boloorforooshan and Markakis, 1979), functional (Oshodi et al., 1999) and health properties (Kapadia et al., 2002; Nakano et al., 2002; Sirato-Yasumoto et al., 2001; Noguchi et al., 2001; Takeuchi et al., 2001). These properties make sesame a valuable source of protein and other nutrients. Currently, their major uses (other than sesame oil pressing) are limited to: garnish of bakery products and in production of Tahina (sesame butter), the later is incorporated in Hummus and eggplant dip. Tahini and sesame are also used in the manufacturing of confectionaries such as Halawa Tahinia and sesame bars (Altschul, 1985). In a recent study (Quasem et al., 2009) in which a basic procedure was proposed for the production of sesame milk, an invention step was suggested concerning the effect of pretreatments of sesame seeds and the effect of sesame seeds source on the quality of the produced milk. The produced sesame milk has acceptable dispersion stability and sensory properties, but there is still a need for further improvement of sesame milk quality. Several studies reported the importance of controlling the ratio of vegetables to water in order to optimize the yield and sensory acceptability. Therefore, the aim of this study was to investigate the effects of interaction between initial sesame seed: water ratio and different pasteurization treatments on the quality of sesame milk.

\section{MATERILAS AND METHODS}

Sesame seed: Decorticated sesame seed (originated from Ethiopia) was obtained from Al-Kasih Factories Group for Food Stuff in Zarqqa/Jordan and characterized as sweet sesame (bitter taste was absent)

Instruments: The following instruments were used throughout the study: blender (Hamilton); homogenizer (Silverson), drying oven (Memmert, Germany); water bath (Model FDP8D, Techne Cambridge Ltd. USA); Kjeldahl Apparatus (Velp scientifica, Italy).

Corresponding Author: Ibrahim Afaneh, Department of Food Science and Technology, Faculty of Science and Technology, Al-Quds University, P.O. Box 20002, Jerusalem-Palestine, Israel

Tel: +972 22796961 Fax: +97222796960 
Preparation of sesame milk: Decorticated sesame seed and tap water were weighed to give the desired sesame seed percentage. Sesame seed was transferred to the blender vessel and a small portion of the weighed water was added to facilitate the progress of mixing/grinding process. The blender was operated at highest speed for $10 \mathrm{~min}$. After finishing the grinding process, the remaining quantity of water was added and mixed thoroughly. The resulted sesame dispersion was homogenized (in portions of $300 \mathrm{~g}$ ) for $5 \mathrm{~min}$ using lab homogenizer. The temperature reached due to homogenization was ca. $52 \pm 2^{\circ} \mathrm{C}$. The homogenized sesame milk base was squeezed through cheesecloth to separate coarse particles. The resulted milky solution was weighed, readjusted to its original weight (before filtration) by adding tap water, sweetened by the addition of $2 \%$ sucrose, mixed thoroughly, filled in a beaker and heated in boiling water bath with manual stirring. The heat-treated milks was filled in $50 \mathrm{~mL}$ presterilized glass tubes $(50 \mathrm{~mL}$ of sesame milk per tube), cooled (by immersing the tubes in ice bath for $5 \mathrm{~min}$ ) and then stored refrigerated (at $\left.4^{\circ} \mathrm{C}\right)$.

\section{Analytical procedures:}

Moisture, protein, ash and fat percentages determination: Moisture, protein $(\mathrm{N} \times 6.25)$, ash and titratable acidity (as lactic acid) were determined by AOAC (1960). Fat was determined using modified Majonnier method (AOAC, 1960).

Total solids yield of sesame milk: Total solids yield of sesame milk was calculated by the following formula: $\%$ Total solids yield $=(($ Percentage of total solids in sesame milk)/(total solids concentration (at weighing step before mixing) $) \times 100$

Protein yield of sesame milk: Protein yield of sesame milk was calculated by the following formula: $\%$ Protein yield $=(($ Percentage of protein in sesame milk $) /$ (Initial protein concentration (at weighing step before mixing) $) \times 100$

Fat yield of sesame milk: Fat yield of sesame milk was calculated by the following formula: $\%$ Fat yield = ((Percentage of fat in sesame milk)/(Initial fat concentration (at weighing step before mixing) $\times 100$

Dispersion stability of sesame milk: As described by Quasem et al. (2009).

Experimental design for dispersion stability of sesame milk experiment: Split plot design $(3 \times 3)$ was used to study the interaction between the two factors. Two replicates were made for each treatment with a sample size of $50 \mathrm{~mL}$ of sesame milk.

Treatments evaluation for dispersion stability of sesame milk experiment: The treatments were evaluated by measuring the dispersion stability in pasteurized sesame milk in each day during the storage period under refrigeration $\left(3\right.$ days at $\left.4^{\circ} \mathrm{C}\right)$.

Statistical analysis for dispersion stability of sesame milk experiment data: All statistical analyses were carried out using SAS (SAS Institute Inc., Cary, USA, Release 8.02, 2001). Comparisons of means with respect to the influence of different sesame seed concentration and different heat treatments were carried out using the GLM procedure considering a split plot design $(3 \times 3)$. The LS-means was employed in order to maintain an experiment wise of 5\% (Steel and Torrie, 1980).

Sesame milk proximate composition, yield and sensory attributes experiment: The proximate composition, yield and sensory attributes were investigated for pasteurized (at $75^{\circ} \mathrm{C}$ for $5 \mathrm{~min}$ ) sesame milks with different initial sesame seed percentages $(10,12$ and $14 \%)$. An experiment was performed to select the optimum level of sugar to be added to sesame milk. This experiment was performed on milk with $12 \%$ initial sesame seed percentage and different levels of sugars $(1,1.5,2,2.5$ and $3 \%$ sucrose). Based on this experiment $2 \%$ sugar was selected as the best level as indicated by the expert panel sensory evaluation. Accordingly, 2\% sugar was added to the three milks with different total solids concentrations. Samples for chemical analysis were drawn before the addition of sugar. Two replicates were made for each treatment and the sample size was $300 \mathrm{~g}$ of sesame milk.

Treatments evaluation for sesame milk proximate composition, yield and sensory attributes experiment: The treatments were evaluated for three tracks:

- Measuring the proximate composition of the produced sesame milk (before the addition of $2 \%$ sugar)

- Measuring sesame milk yield of total solids, protein and fat

- Sensory evaluation using 5-points hedonic scale for the following attributes: aroma, taste, color, mouth feel and overall acceptability 
Statistical analysis for sesame milk proximate composition, yield and sensory attributes experiment data: The data were analyzed statistically by analysis of variance (ANOVA) using: (a) completely randomized design for yield results (b) completely randomized block design for sensory evaluation results. Means separation was done using LSD test with significance at $\mathrm{p}<0.05$. The analysis was performed using SAS system (Steel and Torrie, 1980).

\section{RESULTS AND DISCUSSION}

Dispersion stability: The dispersion stability values of pasteurized sesame milk (Table 1) revealed that the pasteurization treatment at $75^{\circ} \mathrm{C}-5 \mathrm{~min}$ (regardless of the percentages of sesame seed used) generally resulted in higher dispersion stability values in comparison with the other two pasteurization treatments $\left(65^{\circ} \mathrm{C}-30 \mathrm{~min}\right.$ and $\left.85^{\circ} \mathrm{C}-5 \mathrm{~min}\right)$. The only exception was the pasteurized sesame milk produced from sesame milk with $10 \%$ initial sesame seed percentage, which showed slightly (not significant) higher dispersion stability in the second and third day of storage when pasteurized at $65^{\circ} \mathrm{C}-30 \mathrm{~min}$. For this reason, pasteurization treatment at $75^{\circ} \mathrm{C}-5$ min was selected. Regarding the initial percentages of sesame seed, Table 1 shows that the dispersion stability values were significantly increased with increasing the initial sesame seed percentage. To select the optimum initial concentration of sesame seed, additional tests were performed to investigate their effect on milk yield and sensory acceptance.

Table 1: Effect of interaction between different initial sesame percentages and different pasteurization treatments on sesame dispersion stability during storage (at $4^{\circ} \mathrm{C}$ )

\begin{tabular}{|c|c|c|c|c|c|c|c|c|c|}
\hline \multirow{3}{*}{$\begin{array}{l}\text { \% Initial } \\
\text { Sesame seed } \\
\text { Concentration } \\
(\text { as it is*) }\end{array}$} & \multicolumn{9}{|c|}{ Dispersion stability of sesame milk pasteurized at different heat treatments** } \\
\hline & \multicolumn{3}{|c|}{$65^{\circ} \mathrm{C}-5 \mathrm{~min}$} & \multicolumn{3}{|c|}{$75^{\circ} \mathrm{C}-5 \mathrm{~min}$} & \multicolumn{3}{|c|}{$85^{\circ} \mathrm{C}-5 \mathrm{~min}$} \\
\hline & 1st day & 2nd day & 3rd day & 1st day & 2nd day & 3rd day & 1st day & 2nd day & 3rd day \\
\hline 10 & $0.81 \mathrm{c}$ & $0.66 \mathrm{c}$ & $0.59 \mathrm{c}$ & $0.87 \mathrm{~b}$ & $0.64 \mathrm{c}$ & $0.56 \mathrm{c}$ & $0.62 \mathrm{~b}$ & $0.51 \mathrm{c}$ & $0.47 \mathrm{c}$ \\
\hline 12 & $0.88 \mathrm{~b}$ & $0.79 \mathrm{~b}$ & $0.68 \mathrm{~b}$ & $0.95 a$ & $0.87 \mathrm{~b}$ & $0.82 \mathrm{~b}$ & $0.75 \mathrm{a}$ & $0.69 \mathrm{~b}$ & $0.63 b$ \\
\hline 14 & $0.97 \mathrm{a}$ & $0.95 \mathrm{a}$ & $0.93 \mathrm{a}$ & $0.98 \mathrm{a}$ & $0.95 \mathrm{a}$ & $0.95 \mathrm{a}$ & $0.77 \mathrm{a}$ & $0.73 \mathrm{a}$ & $0.70 \mathrm{a}$ \\
\hline
\end{tabular}

*: \% moisture in sesame seed was $4.2 \%$, **: Means within the same column followed by the same letter do not differ significantly (P<0.05)

Table 2: Effect of the using different percentages of sesame seed on proximate composition and yield of the prepared sesame milk

\begin{tabular}{|c|c|c|c|c|c|c|c|c|}
\hline \multirow{2}{*}{$\begin{array}{l}\text { \% Initial } \\
\text { sesame seed } \\
\text { Concentration } \\
\text { (as it is*) }\end{array}$} & \multicolumn{5}{|c|}{ Proximate composition (g $100 \mathrm{~g}^{-1}$ sesame milk) } & \multicolumn{3}{|l|}{ Yield $(\%)^{* *}$} \\
\hline & Total solids & Protein & Fat & Ash & $\begin{array}{l}\text { Nitrogen free extract } \\
\text { by difference }\end{array}$ & Total solids & Protein & Fat \\
\hline 10 & 8.28 & 2.20 & 4.69 & 0.34 & 1.05 & $86.48 \mathrm{a}$ & $87.65 a$ & $87.33 a$ \\
\hline 12 & 9.95 & 2.52 & 5.68 & 0.42 & 1.34 & $86.56 \mathrm{a}$ & $87.64 \mathrm{a}$ & $88.15 \mathrm{a}$ \\
\hline 14 & 11.21 & 2.97 & 6.43 & 0.48 & 1.34 & $83.66 \mathrm{a}$ & $88.77 \mathrm{a}$ & $85.54 \mathrm{a}$ \\
\hline
\end{tabular}

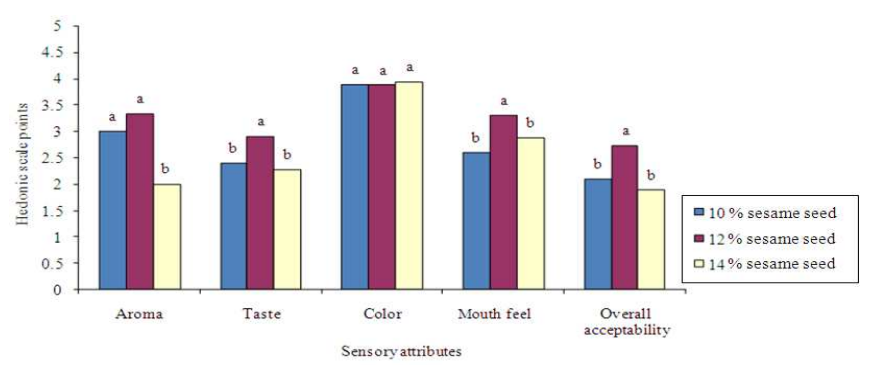

Fig. 1: Effect of different initial sesame seed percentages on sesame milk sensory attributes. Values with different letter within each sensory attribute are significantly different $(\mathrm{p}<0.05)$ according to LSD test

Proximate composition and yield: Results in Table 2 show that there are no significant differences in the percentage of total solids, protein and fat yield between the milks prepared with different initial sesame seed percentages.
Sensory evaluation: Before testing the effect of different initial sesame seed concentration on the acceptability of the produced milks, a pre-experiment was performed to select the best level of sugar (sucrose) in milk started with $12 \%$ sesame seed. The 
result of expert panel test revealed that the optimum sugar concentration was 2\%. Accordingly, 2\% sucrose was added to all samples before pasteurization. Results obtained from the sensory evaluation using 5-points hedonic scale (Fig. 1) indicated that sesame milk with initial sesame percentage of $12 \%$ had a significantly higher overall acceptability score (2.73) than milks with 10 and $14 \%$ initial sesame seed percentages (2.10 and 1.89 respectively).

The milk prepared with an initial sesame seed percentage of $12 \%$ was found to have superior sensory attributes compared to that prepared from $14 \%$ initial sesame seed in terms of aroma, taste and mouthfeel, while they had superior taste and mouthfeel when compared with milk with $10 \%$ initial sesame seed concentration.

\section{CONCLUSION}

This study proved that the initial sesame seed concentration and heat treatment of sesame milk had a significant effect on sesame milk yield and sensory properties. Results indicated that the best sesame seed concentration was $12 \%$ and the best heat treatment was $85^{\circ} \mathrm{C}-5 \mathrm{~min}$.

\section{REFERENCES}

Altschul, A.M., 1985. New Protein Foods. 1st Edn., Academic Press, New York, ISBN-10: 0120548011.

AOAC, 1960. Official Methods of Analysis. 1st Edn., Association of Official Analytical Chemists, Washington, D.C., pp: 832.

Boloorforooshan, M. and P. Markakis, 1979. Protein supplementation of navy beans with sesame. J. Food Sci., 44: 390-391. DOI: 10.1111/j.13652621.1979.tb03795.x

Evans, R.J. and S.L. Bandemer, 1967. Nutritive values of some oilseed proteins. Cereal Chem., 44: 417-426.

Kapadia, G.J., M.A. Azuine, H. Tokuda, M. Takasaki and T. Mukainaka et al., 2002. Chemopreventive effect of resveratrol, sesamol, sesame oil and sunflower oil in the epstein-barr virus early antigen activation assay and the mouse skin two-stage carcinogenesis. Pharmacol. Res., 45: 499-505. PMID: 12162952
Nakano, D., C. Itoh, M. Takaoka, Y. Kiso and T. Tanaka et al., 2002. Antihypertensive effect of sesamin. IV. Inhibition of vascular superoxide production by sesamin. Biol. Pharm. Bull., 25: 1247-1249. PMID: 12230131

Noguchi, T., K. Ikeda, Y. Sasaki, J. Yamamoto and J. Seki et al., 2001. Effects of vitamin E and sesamin on hypertension and cerebral thrombogenesis in stroke-prone spontaneously hypertensive rats. Hypertens. Res., 24: 735-742. PMID: 11768736

Oshodi, A.A., H.N. Ogungbenle and M.O. Oladimeji, 1999. Chemical composition, nutritionally valuable minerals and functional properties of benniseed (sesamum radiatum), pearl millet (pennisetum typhoides) and quinoa (chenopodium quinoa) flours. Int. J. Food Sci. Nutr., 50: 325-331. PMID: 10719563

Quasem, J.M., A.S. Mazahreh and K. Abu-Alruz, 2009. Development of vegetable based milk from decorticated sesame (sesamum indicum). Am. J. Applied Sci., 6: 888-896. DOI: 10.3844/ajassp.2009.888.896

Sirato-Yasumoto, S., M. Katsuta, Y. Okuyama, Y. Takahashi and T. Ide, 2001. Effect of sesame seeds rich in sesamin and sesamolin on fatty acid oxidation in rat liver. J. Agric. Food Chem., 49, 2647-2651. DOI: 10.1021/jf001362t

Steel, R.G.D. and J.H. Torrie, 1980. Principles and Procedures of Statistics: A Biometrical Approach. 2nd Edn., McGraw-Hill, Auckland, ISBN-10: 0070609268, pp: 633.

Takeuchi, H., L.Y. Moot, Y. Inagaki and P. He, 2001. Hypoglycemic effect of a hot-water extract from defatted sesame (Sesamum indicum L.) seed on the blood glucose level in genetically diabetic KK-Ay mice. Biosci. Biotechnol. Biochem., 65: 2318-2321. PMID: 11758931 